\title{
Current Status and Predictors of Diarrhoeal Diseases among Under-Five Children in a Rapidly Growing Urban Setting: The Case of City Administration of Bahir Dar, Northwest Ethiopia
}

\author{
Molla Gedefaw $^{1 *}$, Mengesha Takele ${ }^{2 \#, ~ M e k o n n e n ~ A y c h i l u h e m ~}{ }^{1}$, Molalign Tarekegn ${ }^{1}$ \\ ${ }^{1}$ GAMBY College of Medical Sciences, Bahir Dar, Ethiopia \\ ${ }^{2}$ Organization for Rehabilitation and Development in Amhara, Bahir Dar, Ethiopia \\ Email: "mollagedefaw@yahoo.com, mengeshatakele@yahoo.com, meckachy@yahoo.com, \\ tamolalign@gmail.com
}

Received 6 February 2015; accepted 10 April 2015; published 15 April 2015

Copyright (C) 2015 by authors and Scientific Research Publishing Inc.

This work is licensed under the Creative Commons Attribution International License (CC BY). http://creativecommons.org/licenses/by/4.0/

c) (7) Open Access

\section{Abstract}

Background: Diarrhoeal disease in under-five children is a serious public health challenge especially in low income countries including Ethiopia. In Ethiopia, several interventions are going on to reduce morbidity, and mortality of children. The objective of the study was to assess the prevalence and associated factors of diarrhoeal diseases among under-five children in the City Administration of Bahir Dar. Methods: A community based cross-sectional study was conducted on a sample size of 667 mothers/caregivers having under-five children. Participants were selected through multistage sampling technique. Structured questionnaire and observation checklist were used to collect data. It was analyzed using SPSS version 16 for windows. Logistic regression was applied to measure possible associations. Strength of association, and statistical significance was measured using odds ratio and confidence interval at $95 \%$ confidence level. Results: A total of 667 mothers/ caregivers with under-five children were included in the study. Two-week prevalence of diarrhoea was $21.6 \%$. Households in rural part of the city (OR: 2.82, 95\%CI: $1.66-4.81$ ), monthly income $\leq$ birr 500 (OR: 2.27, 95\%CI: 1.44 - 3.57, failure to use separate container for storing drinking water (OR: 1.78, 95\%CI: 1.17 - 2.70), presence of human excreta in the compound (OR: 1.88, 95\% (1.15 3.06) were found to be predictors of childhood diarrhoea. Conclusion: Diarrhoeal diseases remain serious public health challenge in rural as well as urban set ups in Ethiopia with particular refer-

\footnotetext{
"Corresponding author.

"MPH, BSC, formerly student in joint MPH program, Bahir Dar University, and GAMBY College of Medical Sciences.
} 
ence to Bahir Dar City, despite several interventions over decades. Therefore, interventions, and strategies applied so far to eliminate diseases of poverty including diarrhoeal diseases should be re-visited.

\section{Keywords}

\section{Diarrhoeal Diseases, Prevalence, Under-Five Children, Urban Setting}

\section{Introduction}

The health of under-five children is a major health challenge worldwide. To alleviate the problem, several interventions have been tried for the past two decades. Though there was substantial progress in reducing mortality rate, from 87 deaths per 1000 live births in 1990 to 51 in 2011, the pace has been slow or even reversing, particularly in many sub-Saharan African countries [1]. Of the estimated 10.6 million under-five deaths worldwide, about 42 percent occur in African region. This figure is seven times higher than the burden in the European region [2] [3]. Ethiopia ranked among the top five countries in the world in the absolute number of annual deaths in under-five children [4].

Diarrhoea has been a potential bottle-neck in reaching the Millennium Development Goal (MDG) target. Together with pneumonia, it is responsible for $29 \%$ of all child deaths [5] [6]. The burden of childhood diarrhoea in Ethiopia is well known. Several epidemiologic studies were conducted [7]-[12]. Findings of these studies indicated that diarrhoeal disease in children was one of the highest in the world, and it is mostly associated with personal and environmental hygiene.

Currently, several interventions are going on to reduce child morbidity, and mortality in Ethiopia. According to the report of Federal Ministry of Health, water supply and sanitation coverage has increased. Health extension package has been implemented and scaled up for both rural and urban areas in the country which aims to empower the community to prevent classical infectious and parasitic diseases [13]. By implication, these interventions are expected to decrease diseases of poverty such as diarrhoea, intestinal worm infestation, and trachoma.

Most of these studies conducted in Ethiopia focus on rural areas [7]-[12]. Therefore, data are needed to see the progress especially in urban areas. The current study aimed at determining the magnitude and associated factors of diarrheal disease in the city administration of Bahir Dar. The finding of this study would help decision makers know the current prevalence of childhood diarrhoea which could in turn serve as a mirror to reflect successes or failures of interventions applied so far. The lesson derived from the disparities of interventions vis-àvis outcomes regarding health gains could pass meaningful messages for international readers too.

\section{Methods}

\subsection{Study Design and Area}

Community based cross sectional study was conducted in the city administration of Bahir Dar, the capital of Amhara National regional Sate. It is a rapidly growing city in the country where you can observe infrastructure distribution inequalities. The total population of the City Administration was estimated to be 267,350. Of which, 219,585 were living in urban and 47,765 were in rural part of the city. According to the current census, total number of under-five children in all sub cities of the city administration was 11,776. Of these, 7919 were living in urban and 3857 were in rural part of the city administration [14].

\subsection{Target Population}

Target population for this study was mothers with under-five children residing in the city for at least six months prior to the survey.

\subsection{Sample Size}

Sample size was determined by single population proportion formula. The assumptions were two-week period 
prevalence of diarrhoea (15\%), margin of error (4\%), design effect (2), confidence level (95\%) and anticipated non response rate (10\%). The size of participants for this study was 673 .

\subsection{Sampling Procedure}

A total of 673 households (505 from urban and 168 rural) where at least one under-five child were present based on family folder developed by health extension workers were selected using systematic random sampling method.

\subsection{Data Collection Procedures}

Face to face interview was done using a pretested structured questionnaire, and observation was made using observation checklist.

\subsection{Data Quality Assurance}

Data quality was assured by the following mechanisms. Questionnaire was adopted from previous studies in Ethiopia, and translated to local language and back to English to assure consistency of the questionnaire. Pre-test was done, and minor corrections were amended. Data collectors were selected who have educational attainment of grade 10 plus 3 years professional training, and have experience in data collection. Training had been given for data collectors and supervisors. Supervisors were BSc. Professionals. Each questionnaire was checked on daily basis for completeness.

\subsection{Operational Definition}

In this survey, if an under-five child was reported to have loss or watery stool at least three times per day, and at least once in the past two weeks prior to the study, the child was declared to have diarrhoea.

\subsection{Data Analysis}

The collected data were coded, entered, cleaned, and analysed using SPSS version 16 for windows. Bi-variate analysis was used to determine possible association between an independent and the outcome variable. Variables with statistical significance level of p-value of 0.3 or less were entered into the multivariable analysis model. Odds ratio with 95\%CI was used to measure the strength of association, and statistical significance.

\subsection{Ethical Considerations}

Ethical clearance was obtained from Ethical Clearance Committee of Bahir Dar University and permission letter was also obtained from the Regional Health Bureau. Verbal consent was obtained from each caregiver of the child.

\section{Results}

\subsection{Characteristics of Under-Five Children in the City Administration of Bahir Dar, Northwest Ethiopia}

With $51.7 \%$ of the children were males. About $26 \%$ of children were within the age group of 12 - 23 months. In the current study, two weeks prevalence of diarrheal disease among under-five children was $21.6 \%$ (Table 1 ).

\subsection{Socio-Economic \& Demographic Characteristics of Mothers/Caregivers in Bahir Dar City Administration, Northwest Ethiopia}

Six hundred sixty seven caregivers were included in the study. The study had a response rate of $99.1 \%$. Majority (76\%) were urban dwellers, and $71 \%$ of them were housewives. More than $54 \%$ of the caregivers were illiterate and about $44 \%$ earned a monthly income of Birr 500 or less (Table 2). 
Table 1. Characteristics of under-five children, and two weeks prevalence of diarrhoea in the city administration of Bahir Dar.

\begin{tabular}{lcc}
\hline \multicolumn{1}{c}{ Variables } & \multicolumn{2}{c}{ Frequency } \\
\cline { 2 - 3 } & Number & Percent \\
\hline Sex of children & 345 & 51.7 \\
$\quad$ Male & 322 & 48.3 \\
$\quad$ Female & & \\
Age of children (month) & 47 & 7.0 \\
0 - 5 & 93 & 13.9 \\
6 - 11 & 172 & 25.8 \\
$12-23$ & 137 & 20.5 \\
$24-35$ & 125 & 18.7 \\
$36-47$ & 93 & 13.9 \\
48 - 59 & & \\
Occurrence of diarrhoea in the past two weeks & 144 & 21.6 \\
Yes & 523 & 78.4 \\
$\quad$ No & & \\
\hline
\end{tabular}

Table 2. Socio-economic \& demographic characteristics of households which have under-five children, Bahir Dar City administration, June, 2012.

\begin{tabular}{|c|c|c|}
\hline \multirow{2}{*}{ Variables } & \multicolumn{2}{|c|}{ Frequency } \\
\hline & Number & Percent \\
\hline \multicolumn{3}{|l|}{ Residence } \\
\hline Rural & 163 & 24.4 \\
\hline Urban & 504 & 75.6 \\
\hline \multicolumn{3}{|l|}{ No. under- 5 children in a $\mathrm{HH}$} \\
\hline One & 570 & 85.5 \\
\hline Two \& above & 97 & 14.5 \\
\hline \multicolumn{3}{|l|}{ Age of mothers/caregivers } \\
\hline 15 - 24 years & 184 & 27.6 \\
\hline 25 - 34 years & 332 & 49.0 \\
\hline 35 - 49 years & 132 & 19.8 \\
\hline$>49$ years & 19 & 2.8 \\
\hline \multicolumn{3}{|c|}{ Educational status of mothers/caregivers } \\
\hline Unable to and write & 360 & 53.9 \\
\hline Primary & 137 & 20.5 \\
\hline Secondary and above & 170 & 25.5 \\
\hline \multicolumn{3}{|l|}{ Occupation of mothers/caregivers } \\
\hline House wife & 473 & 70.9 \\
\hline Farmer & 161 & 24.1 \\
\hline Government employee & 33 & 4.9 \\
\hline \multicolumn{3}{|c|}{ Educational status of fathers $(n=599)$} \\
\hline Unable to read and write & 189 & 28.3 \\
\hline Primary & 213 & 31.9 \\
\hline Secondary and above & 197 & 29.5 \\
\hline \multicolumn{3}{|l|}{ Monthly income } \\
\hline Birr 500 or less & 295 & 44.2 \\
\hline Birr 501 - 1500 & 291 & 43.6 \\
\hline Birr 1500+ & 81 & 12.1 \\
\hline
\end{tabular}




\subsection{Environmental Characteristics of Studied Households in Bahir Dar City Administration, Northwest Ethiopia}

About eleven percent of households have animals which share the same house/room. Nearly $70 \%$ of households had latrine facility; however, only (16.2\%) had hand washing facility.

Majority of households (83\%) obtained drinking water from pipe and protected schemes while the remaining. About $60 \%$ of households had water source at home. Majority of households $(68 \%)$ consumed $\geq 15$ litters per day (Table 3).

\subsection{Behavioural Characteristics of Households Which Have Under-Five Children, Bahir Dar City Administration, Northwest Ethiopia}

About ninety seven percent of households claimed to use latrine facility. However, human excreta were observed in the compound and around the latrine in nearly $27.6 \%$ and $22.4 \%$ of households. In about $30 \%$ of the households, dry west disposal was collected and disposed at disposal pit while $76.8 \%$ of households disposed their liquid waste in open field. Majority (91.6\%) of the caregivers claimed not to wash their hands after or before every critical times of hand washing such as before eating, and food preparation or after cleaning a child or visiting toilette (Table 4).

\subsection{Factors Associated the Occurrence of Diarrheal Disease among Under-Five Children in the City Administration of Bahir Dar, Northwest Ethiopia}

Multivariate logistic regression revealed that rural residence (OR: 2.82, 95\%CI: 1.66 - 4.81), monthly income of birr 500 or less (OR: 2.27, 95\%CI: 1.44 - 3.57), birr 501 - 1500 (OR: 3.39, 95\%CI: 1.58 - 7.27), failure to use separate container for storing drinking water (OR: 1.78, 95\%CI: 1.17 - 2.70) and human excreta in the compound (OR: 1.88, 95\%CI: 1.15 - 3.06) were found to have statistically significant association with occurrence diarrhoeal disease among under-five children (Table 5).

\section{Discussions}

The major objective of the present study was to assess prevalence and correlates of diarrheal disease among under-five children in an urban set up. It revealed that the two weeks prevalence of diarrhoea was $21.6 \%$. This finding was in line with the findings in Adami Tulu [7], North Gondar district [8] and Mecha district [9] where the prevalence rate was $22.7 \%, 20.7 \%$, and $18 \%$, respectively. Previous reports from Southwest Ethiopia (Nekemte, 2008) [10] and (Mana district, 2000) [11] where the prevalence was $28.9 \%$ and $33.7 \%$, respectively were even worse than findings of the current study. The present study reconfirms that diarrhoeal diseases in under five children remains rampant in rural as well as in urban set ups.

The fact that the prevalence in the current study is similar to reports from Adame Tulu (1996) [7] and North Gondar Zone (2001) [8] clearly demonstrated that changes are very minimal over decades, and Ethiopia has a long way to go to eliminate this disease of poverty.

The most important predictors of diarrhoea in under-five children were personal and environmental hygiene as well as socioeconomic factors. Children from rural households were 2.82 times (95\%CI: 1.66, 4.81) more likely to experience diarrhoea than those in urban households. This result was in line with the finding in Keffa Sheka Zone [12]. This might be associated with differences in access to water, sanitation and hygiene. The access for the above services in urban setting was better than that in rural settings. Hence this difference might be responsible for the low prevalence of diarrheal disease among under-five children in urban setting compared with the prevalence in those who were rural [15].

Children from households whose monthly income was below 1500 Ethiopian birr were at a higher risk to develop diarrhoea than in those who earn above 1500 Ethiopian birr. This was also in agreement with the findings in Keffa Sheka and Eritrea [12] [16].

In addition, children in households where human excreta was observed in the compound were 1.89 times (95\%CI: 1.159, 3.07) more likely to develop diarrheal diseases than in those where no human excreta was observed. This finding was in line with the study undertaken in Nekemte [10]. This is logical that improper disposal of human excreta increases the chance for pathogenic microorganisms including the causes of diarrheal diseases to infect humans especially children [17]. 
Table 3. Environmental characteristics of households, Bahir Dar City administration.

\begin{tabular}{|c|c|c|}
\hline Variables & Frequency & Percent \\
\hline \multicolumn{3}{|c|}{$\begin{array}{l}\text { Existence of animals in the same house/room with } \\
\text { the household }\end{array}$} \\
\hline Yes & 70 & 10.5 \\
\hline No & 597 & 89.5 \\
\hline \multicolumn{3}{|l|}{ Floor of the house } \\
\hline Soil & 592 & 88.8 \\
\hline Ceramic & 75 & 11.2 \\
\hline \multicolumn{3}{|l|}{ No. of rooms in the living house } \\
\hline One & 286 & 42.9 \\
\hline Two & 381 & 57.1 \\
\hline \multicolumn{3}{|l|}{ Availability of latrine in the house $(n=463)$} \\
\hline Yes & 463 & 69.4 \\
\hline No & 204 & 30.6 \\
\hline \multicolumn{3}{|l|}{ Ownership of latrine $(n=463)$} \\
\hline Private & 236 & 51.0 \\
\hline Communal & 227 & 49.0 \\
\hline \multicolumn{3}{|l|}{ Type of latrine $(n=463)$} \\
\hline Traditional & 398 & 86.0 \\
\hline Modern & 65 & 14.0 \\
\hline \multicolumn{3}{|c|}{$\begin{array}{l}\text { Availability of hand washing facility in the latrine } \\
(\mathrm{n}=463)\end{array}$} \\
\hline Yes & 75 & 16.2 \\
\hline No & 388 & 83.8 \\
\hline \multicolumn{3}{|l|}{$\begin{array}{l}\text { Availability of traditional hand dug well in the } \\
\text { compound }\end{array}$} \\
\hline Yes & 75 & 11.2 \\
\hline No & 592 & 88.8 \\
\hline \multicolumn{3}{|l|}{ Location of the well from the latrine } \\
\hline In the lower side from the latrine & 26 & 34.7 \\
\hline Same level side by side with the latrine & 33 & 44.0 \\
\hline Upper side of the latrine & 16 & 21.3 \\
\hline \multicolumn{3}{|l|}{ Distance between the well and latrine } \\
\hline Below $15 \mathrm{~m}$ & 19 & 25.3 \\
\hline From $15-30 \mathrm{~m}$ & 23 & 30.7 \\
\hline Above $30 \mathrm{~m}$ & 33 & 44.0 \\
\hline \multicolumn{3}{|l|}{ Source of drinking water } \\
\hline Pipe \& other protected schemes & 555 & 83.2 \\
\hline Unprotected sources & 112 & 16.8 \\
\hline \multicolumn{3}{|l|}{ Distance between the water source and house } \\
\hline In the compound & 421 & 63.1 \\
\hline Purchasing from neighbour & 76 & 11.4 \\
\hline Less than 20 minutes & 85 & 12.7 \\
\hline$\geq 20$ minutes & 85 & 12.7 \\
\hline \multicolumn{3}{|l|}{ Per capita water consumption } \\
\hline$\geq 15$ litters & 453 & 67.9 \\
\hline$<15$ litters & 214 & 32.1 \\
\hline
\end{tabular}


Table 4. Behavioural characteristics of caretakers with under-five children in the city administration of Bahir Dar, June, 2012.

\begin{tabular}{lcc}
\hline \multicolumn{2}{c}{ Variables } & \multicolumn{2}{c}{ Frequency } \\
\cline { 2 - 3 } & Number & Percent \\
\hline Latrine use practice $(\mathrm{n}=463)$ & 450 & 97.2 \\
$\quad$ Always & 13 & 2.8 \\
$\quad$ Sometimes & & \\
Human excreta around the latrine $(\mathrm{n}=463)$ & 103 & 22.4 \\
$\quad$ Yes & 360 & 77.6 \\
$\quad$ No & & \\
Human excreta in the compound $(\mathrm{n}=667)$ & 184 & 27.6 \\
$\quad$ Yes & 483 & 72.4 \\
$\quad$ No & & \\
Material used for washing hands in all critical times \\
(n = 667)
\end{tabular}

Table 5. Predictors of diarrheal diseases among under-five children in city administration of Bahir Dar, June, 2012.

\begin{tabular}{|c|c|c|c|c|}
\hline \multirow{2}{*}{ Variables } & \multicolumn{2}{|c|}{ Diarrheal disease } & \multirow{2}{*}{ Crude OR $(95 \% \mathrm{CI})$} & \multirow{2}{*}{ Adjusted OR (95\%CI) } \\
\hline & Yes & No & & \\
\hline \multicolumn{5}{|l|}{ Residential area } \\
\hline Rural & 56 & 107 & $2.47(1.66-3.68)^{*}$ & $2.82(1.66-4.81)^{*}$ \\
\hline Urban & 88 & 416 & 1.00 & 1.00 \\
\hline \multicolumn{5}{|l|}{ Household monthly income } \\
\hline Birr 500 or less & 82 & 213 & $1.81(1.22-2.69)^{*}$ & $2.27(1.44-3.57)^{*}$ \\
\hline Birr 501 - 1500 & 51 & 240 & $2.45(1.23-4.85)^{*}$ & $3.39(1.58-7.27)^{*}$ \\
\hline Birr 1500+ & 11 & 70 & 1.00 & 1.00 \\
\hline \multicolumn{5}{|c|}{ Separate container for storing drinking water } \\
\hline Yes & 84 & 365 & 1.00 & 1.00 \\
\hline No & 60 & 158 & $1.65(1.13-2.41)^{*}$ & $1.78(1.17-2.70)^{*}$ \\
\hline \multicolumn{5}{|c|}{ Human excreta in the compound } \\
\hline Yes & 63 & 121 & $2.58(1.75-3.81)^{*}$ & $1.88(1.15-3.06)^{*}$ \\
\hline No & 81 & 402 & 1.00 & 1.00 \\
\hline
\end{tabular}


A lot has been said about success of Ethiopian Health System especially following implementation of Health Extension Package [18] [19]. Nearly 40,000 health workers are deployed across the nation to give health education by going house to house. The final goal of this mammoth national undertaking in Ethiopia is to empower households to prevent classical poverty diseases. However, the prevalence of classical poverty diseases such as diarrhoea [7]-[12], intestinal parasites [20] trachoma [21] remains rampant. According to these studies, prevalence of childhood diarrhoea ranged from about $18 \%$ to over $30 \%$ while intestinal parasites and trachoma had a $70 \%$, and nearly $25 \%$, respectively.

This disparity between investment in health and comparatively low outcome in health gain require through investigation for it will be the basis for future planning.

The most important limitation of this study is that it is not supported with identification of aetiologies of diarrhoeal diseases in the study area in addition to the limitation of the study design-cross sectional. Moreover, the strength of this study design could have been enhanced had it been supported with qualitative data to answer the why questions.

\section{Conclusion}

Despite several interventions over decades, diarrhoeal diseases remain serious public health challenge in rural as well as urban set ups in Ethiopia with particular reference to Bahir Dar City. Therefore, interventions and strategies applied so far to eliminate diseases of poverty including diarrhoeal diseases should be re-visited.

\section{Acknowledgements}

We are very grateful to Bahir Dar University, and GAMBY College of Medical Sciences for opening Joint MPH program which motivated the staff to be engaged in research work. We thank the Regional Health of Amhara National regional Sate for writing permission letter. We would like to extend our heartfelt gratitude to study participants, data collectors, and supervisor without their cooperation this work could not have been completed.

\section{Conflict of Interest}

There is no any conflict of interest.

\section{References}

[1] Young, M., Wolfheim, C., Marsh, D.R. and Hammamy, D. (2012) World Health Organization/United Nations Children's Fund Joint Statement on Integrated Community Case Management: An Equity-Focused Strategy to Improve Access to Essential Treatment Services for Children. American Journal of Tropical Medicine and Hygiene, 87, 6-10. http://dx.doi.org/10.4269/ajtmh.2012.12-0221

[2] Bryce, J., Boschi-Pinto, C., Shibuya, K. and Black, R.E. (2005) WHO Estimates of the Causes of Death in Children. Lancet, 365, 1147-1152. http://dx.doi.org/10.1016/S0140-6736(05)71877-8

[3] WHO (2005) Mothers and Children Matter—So Does Their Health. Make Every Mother and Child Count, Geneva. www.who.int/whr/2005/whr2005_en

[4] Larson, T. and Ketsela, C.P. (1993) The Ecology of Health and Disease in Ethiopia. Acute Childhood Diarrhea, Westview Press, Oxford, 203-210.

[5] PATH (2009) The Deaths of Nearly 1.6 Million Children Annually Diarrheal Disease: Solutions to Defeat a Global Killer. www.path.org/publications/files/IMM_solutions_global_killer

[6] The United Nations Children's Fund (UNICEF)/World Health Organization (WHO), Diarrhea (2009) Why Children Are Still Dying and What Can Be Done. www.unicef.org/health/index 51412.html

[7] Tesfaye, F., Enqusellassie, F.F. and Wendimagegn, G. (1996) ORS Usage in Acute Childhood Diarrhoea, Adami-Tulu Woreda. Ethiopian Medical Journal, 34, 51-54.

[8] Mitike, G. (2001) Prevalence of Acute and Persistent Diarrhoea in North Gondar Zone, Ethiopia. East African Medical Journal, 78, 46-48. http://dx.doi.org/10.4314/eamj.v78i8.8997

[9] Dessalegn, M., Kummie, A. and Tefera, W. (2011) Predictors of Under-Five Childhood Diarrhea: Mecha District, West Gojam, Ethiopia. Ethiopian Journal of Health Development, 25, 100-173.

[10] Girma, R., Wondwosen, B., Bishaw, D. and Tefera, B. (2008) Environmental Determinants of Diarrhea among UnderFive Children in Nekemte Town, Western Ethiopia. Ethiopian Journal of Health Sciences, 18, 1-4. 
[11] Kaba, M. and Ayele, F. (2000) Ethnographic Study of Diarrheal Diseases among Under-Five Children in Mana District, Jimma Zone, Southwest Ethiopia. Journal of Health Development, 14, 77-84. http://dx.doi.org/10.4314/ejhd.v14i1.9932

[12] Teklemariam, S., Getaneh, T. and Bekele, F. (2000) Environmental Determinants of Diarrhoea Morbidity in UnderFive Children. Keffa-Sheka Zone. Ethiopian Medical Journal, 38, 27-34.

[13] (2010) Federal Democratic Republic of Ethiopia, Ministry of Health, Health Sector Development Program IV, 2010/11-2014/15 Final Draft.

[14] City Administration of Bahir Dar Health Office (2011/2012) Unpublished Document, Annual Report.

[15] J-PAL (2012) J-PAL Urban Services Review Paper. Abdul Latif Jameel Poverty Action Lab, Cambridge. http://www.povertyactionlab.org/publication/improving-access-urban-services-poor

[16] Woldemichael, G. (2001) Diarrheal Morbidity among Young Children in Eritrea: Environmental and Socioeconomic Determinants. Journal of Health, Population and Nutrition, 19, 83-90.

[17] (2014) Armed Forces Pest Management Board Information Services Division Forest Glen Section/Walter Reed Army Medical Center Washington, DC 20307-5001, Significance, Surveillance and Control in Contingency Operations. 2001. http://www.afpmb.org/sites/default/files/pubs/techguides/tg30

[18] (2014) All Eyes on Ethiopian Ethiopian’s National Health Extension program, USAID.

[19] http://www.theguardian.com/global-development/2014/jan/09/ethiopia-model-families-social-transformation-healthcare

[20] Ketema, K., Tiruneh, M., Woldeyohannes, D. and Muluye, D. (2012) Active Trachoma and Associated Risk Factors among Children in Baso Liben District of East Gojjam, Ethiopia. BMC Public Health, 12, 1105. http://dx.doi.org/10.1186/1471-2458-12-1105

[21] Fentie, T., Erqoub, S., Gedefaw, M. and Desta, A. (2013) Epidemiology of Human Fascioliasis and Intestinal Parasitosis among Schoolchildren in Lake Tana Basin, Northwest Ethiopia. Transactions of the Royal Society of Tropical Medicine and Hygiene, 107, 480-486. http://dx.doi.org/10.1093/trstmh/trt056 